\title{
Exploring the Connection Between Environmental Catastrophe and the Human Way of Life in the Scope of Green Literature
}

\author{
Thejas Gigy Thomas and Prasantha Kumar N. S. \\ Department of English, School of Social Sciences and Languages, Vellore \\ Institute of Technology, Vellore, Tamil Nadu, India
}

\begin{abstract}
Humans have evolved physically, psychologically, socially, and culturally in the evolution of mankind. Through our civilization, we saw many peaks and troughs. Scientific discovery and industrial progress have been landmarks in this historical growth of our society. This study explores the connection between the ecological crisis as well as the style of human society. While both achieving and thriving have pleasures and necessities, it also altered our consciousness by establishing social order. Invariably, this class hierarchy generated the incentive for social standing by obscuring humankind's well-being. The individualistic approach excluded the factor of connection with one another and with nature. We have plundered the earth's riches, destroyed its glory, and led all beings into a disharmonious state of affairs. We have to change our inner identity in order to transform the world. The study thus explains the ideology of anthropocentrism and the steps that will be introduced to make a sustainable society and protect this mother earth.
\end{abstract}

KEY WORDS: WORLD, ENVIRONMENT, DESTRUCTION, LITERATURE, MANKIND, IDENTITY, SOCIETY.

\section{INTRODUCTION}

Since the second half of the 20th century, ecocriticism has been a matter of concern. Ecologists, environmentalists, and ecocritics have both believed and acknowledged profoundly that the time has come to preserve the world from erosion, desertification, toxic contamination and species extinction as well as the biodiversity of nature, ecology and atmosphere. Ecocriticism is usually defined as applying ecological concepts in terms of its role, ecosystems and the environment to the literary portrayal. To emphasize the sense of a balanced environment based on the pleasant interaction between humans and biotic and abiotic elements, a holistic approach is required. The burden of ecocriticism lies in the inviolable relation between human and non-human worlds, which demands that one does not survive without the other. William Rueckert, Lawrence Buell's and Cheryll Glotfelty's views are considered significant in the ecocritical debate of the 20th century to reject the anthropocentric ignorance

Biosc Biotech Res Comm P-ISSN: 0974-6455 E-ISSN: 2321-4007

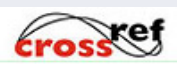

Identifiers and Pagination

Year: 2021 Vol: 14 No (8) Special Issue

Pages: $15-19$

This is an open access article under Creative

Commons License Attribn 4.0 Intl (CC-BY). DOI: $h t t p: / / d x$.doi.org/10.21786/bbrc/14.8.4 of people and encourage ecocentric understanding and holistic approach.

While Rueckert shows the notion of environmental principles to research in Literature and Ecology: An Experiment in Ecocriticism (1978), Glotfelty emphasises the approach of literature studies in The Ecocriticism Reader: Landmarks in Literary Ecology, 1996. On the other hand, Buell in The Future of Environmental Criticism, 2005 presents four essential parameters for literature research: the human and non-human world's good and intertwined relationship, the rejection of the human world's supremacy over the natural universe; the duty of the human world to the non-human world, and the focus on the ecosystem as a mechanism instead of a system (Rueckert, 1996).

When science evolved, we were quickly manipulating the universe. We were dependent on agriculture until the industrial revolution and we worshipped our nature for its selfless generosity of gifts to mankind. It exerted its dominance over modern culture in its way as industrial society took over all the economic influence of feudal society. It built our minds and directed our interests, society's laws and rules, what to like and hate (Altieri, 1995). The emergence of the class structure provided wishes for greater ideals to acquire and crave. It deliberately developed the awareness of the working class to ascend the imperialist ladder and stay at their level to
Article Information

Received: 09 ${ }^{\text {th }} \mathrm{Apr} 2021$

Accepted after revision: $15^{\text {th }}$ June 2021 
rule other ordinary workers. Our way of life and beliefs have evolved in human cultures over the years as we traceback. In constructing innovations and transforming the way of living, Europe played a significant part. The assimilation task they have been using to suggest that we have the responsibility of humanizing the rest of the planet has had a larger effect on the rest of the community.

They also exhumed the riches of colonized nations throughout the name of humanity. The Heart of Darkness by Joseph Conrad shows the harm they have done to mankind as well as to itself. We've effectively shifted from the need to lust. To fulfil the built craving, the goods were produced in bulk. This desire for commodities has contributed to the degradation of the world. As the craving for materials expanded, environmental degradation rose in exact correlation (Giblett, 1996). The number of trees we cut, the number of cars we use on land, in the sky as well as on the sea for transport have increased emissions and impacted biodiversity. Today, without understanding how much it costs, particularly ecological contamination, we want stuff from the various regions of the globe instantly. Without knowing the implications, we have generated its use and toss away culture inside us.

Another of the foremost reasons for many other ecological imbalances is anthropocentric culture. Four of the key crises that we need to resolve urgently are global warming, depletion of wildlife, environmental issues or pollution and the problem of water. All of these have emerged to our doorsteps, and we will be witnessing this in our daily lives today. At the earliest, we have to resolve all these biggest priorities. We ought to recognize that many are seriously addressing the issues, particularly some of the non-governmental organizations, and even some of the representatives have chosen to take the concerns as vital problems to discuss. To avoid complications, the United Nations and some countries have also taken measures. But a person's responsibilities to Mother Earth are indispensable.

The Link Between Ecological Catastrophe And Human Lifestyles: Humanity has now reached a new age in science. We enjoy all the benefits of our ancestors who are responsible for the tremendous waves of progress by supplying technology, machinery, steam engines, mobile phones, telecommunications, travel networks, etc. to lay the basis for the pleasures and amenities of mankind. In science, the technological age, quantum computing, etc., we are all exceptional. All this reveals humanity's opportunities but recognizes the pursuit of imagination. Humanity and even the human race have been affected by this velocity of change. Although the transition is vital for survival, the very rapid pace of change has placed us in a difficult situation to solve the issues of widely accepted good and sustainable social progress. Our lifestyle has changed today because of sudden growth in all of these areas. It has influenced both modern existence and the whole ecosystem.
It could be said that most of today's country's problems originate from the tendency, sometimes unconscious, to make scientific community and technology's methods and goals a metaphysical paradigm that shapes human livelihoods and society's functions. As we have encountered the detrimental nature of this type of epistemology that is governed by the powerful for their vested interest, it is very essential to inspect who is trying to guide this understanding. One example could be the exploration of nuclear power and its use (Kincaid, 1999) We know that both humanity and ecology are threatened, but our ideas are obscured with misconceptions of growth and physical strength. Today's capitalism isn't obsessed with mankind's well-being, where all the fundamental needs are met for all, rather they are involved in extracting benefit. The industry does not guarantee a secure environment and essential social evolution for the future.

It continually distracts human minds and sets in motion an increased appetite for new experiences. The development of the mind media has played an important role in this area. Capitalists inevitably dominate the media and they excel in spreading their agenda of creating the class structure for their economic benefit and suppressing the dissemination of any of the threatening facts, such as the environmental crisis. We also surrender to finding soothing and exciting data that is all about the virtual environment. Dr. Hannah Hamilton of Kenyon College figures out that when people have very little influence over the result, the anxiety generated by worrying about environmental issues can be especially strong. Since one person alone does not solve the problem, and only one action is just not enough, individuals are especially likely to seize up and overlook the question. We also limited ourselves to individualism, not thinking about what's going to happen next door. So, we don't care about what's going on in the Polar Areas, so we don't experience it explicitly. We are not even in immediate communication with the issues. The damage caused by the impact of each state in India on global warming is not seen, which renders us oblivious to the issues. The individualistic way of life drives one to reckless individuals when it comes to the general welfare.

While educational institutions have taken a particular interest in carrying out tasks and slathering ecological crisis content, this is just becoming a practice. Students are worried about the burden of cultivating a shrub and taking good care of it (Haraway, 1999). Education is primarily based on livelihood rather than enjoyment of nature or ecological improvement and sustainable interest. For several proposals, for example, the plastics we use and throw, which are not recycled, we mostly use non-renewable substances are of greater importance today. Any of the coasts of the sea are poisoned by plastics that do not control human conscience. The problem of water has been a huge challenge for all of us. As rightly stated by Samuel Coleridge in his poem "The Rime of the Ancient Mariner"; 
"Water, water, everywhere,

And all the boards did shrink;

Water, water, everywhere,

Nor any drop to dink." (The Rime of the Ancient Mariner, 1798)

Today's background in which there is water but full of misery is relevant to this poem. People don't have any good drinking water. In comparison, water has become a resource where people are selling it and benefit from it. The safety of water available to the vulnerable is an especially serious problem. Many diseases and the outbreak of water-related illnesses, including those caused by microbes and chemical compounds, occur from contaminated water every day. A major cause of deprivation and infant mortality is dysentery and cholera, related to poor sanitation and water sources. In several places, groundwater sources are harmed by the pollutants caused by certain quarrying, agricultural and industrial activities, particularly in countries that lack sufficient legislation or control mechanisms. It is not just about polluted air, but also because of deforestation mostly on river banks, freshwater is now being lessened. The Cauvery River in Karnataka, for example, is being cut due to deforestation and land degradation depletion despite the constant need for fertilizers in farm areas. For a warmer lifestyle, we could seek out a few approaches, such as:

1. To increase people's awareness of the relationship between water and life and to promote common water conservation initiatives;

2. Push the government to adopt a proactive strategy on water use and to centralize and reinforce current institutions of water conservation;

3. To review the harm already done, to identify issues for thorough analysis, and to improve water quality rejuvenation practices;

4. Reviving and propagating ancient methods of water management and adaptive fisheries policies;

5. To create a network of all those who are connected with these problems.

We will be in the midst of the greatest period of extinction of species over the last 60 million years. Usually, between one and five species yearly go extinct. Scientists estimate, however, that we're already losing species at between 2,000 and 10,000 times the regular rate, with constant news species extinction. Before we learn about them or the advantages they carry to our cosmos, multiple species will vanish. Human influence has led to an increase in biodiversity being lost. Invariably, our short-sighted framework to substantial products has led everyone to cut down forests that are home to several species. The ecosystem that will be useful to us in the coming years is generously unearthed. The use of too many plants that will be very beneficial to our children is not known to us. We recognize that everything in existence is interdependent. The depletion of every ecosystem would cost humanity a great deal. The disappearance of birds or insects, since they are actively interested in our agriculture, will result in the loss of mankind itself.
Any extinction of biodiversity thus lands us in a very serious situation.

We ought to establish a far-sighted biodiversity management strategy because we are involved in immediate benefit and enjoyment. Our culture has changed so much that we suddenly need something. We could not search for long-term profit in the future (Shiva, 1988). We are taught to believe in our nation as an imaginary frontier, which then in turn helps us not care about what is happening at the time of the fence. We recently learned that under a fire attack, the Amazon forest barely became a problem for many politicians from various regions of the continent. We somehow ignored it despite recognizing that Amazon comprises broad biodiversity, supplies 20 percent of oxygen and home to edible herbs. We have indeed sought to create a connection between ecological disaster and sustainability practices. Now let's reflect on what are some of the steps that should be taken to avert an environmental crisis?

\section{Actions for a Safe and Environmentally Sustainable} Living: First and foremost, eco-friendly anthropology needs to be established. Without proper anthropology, there can be no environmentalism. It is time for humans, like all other species, to deconstruct our notion of anthropocentrism as the masters of the universe into part of existence. In nurturing and safeguarding nature, we should regard ourselves as conscientious co-creators. Any disruption or malicious intent will kill us by embracing the idea that everything in existence is intertwined. There is no improvement until, with deliberate commitment, we change our lifestyle. Reasonable external arrangements are desperately needed since certain local councils are not capable of successful action. Policies must be free of bureaucracy and governance from pressure (Ravindranath, 2011). It is important to transform society through minimal production and consumption over wasteful production, over-consuming mindset use and throwing away because we know that there are enough products to meet the needs of everyone in the world.

It is essential to stimulate renewable energy use. Very little use of non-renewable energy must be noted by international leaders and some fuel and automobile use laws should be made. It is necessary to encourage individuals to use the seasonal food of a particular place wherein they live. Sea creatures and water pollution may be disrupted by extensive imports and exports across the sea. At the local level, the emphasis needs to be on energy conservation, waste control, sustainable farming development, waste disposal, water supply conservation, local retail coordination, well-controlled drainage and, most critically, growing enough trees to preserve the environment (Buell, 2005). Community and schoollevel curriculum need to be more focused on building eco-friendly knowledge and appreciation for nature. For the environmentalist, educational institutions have to give time. The idea of sustainability must be revised in the minds of children that improving the well-being of everyone, namely all other species, is not constructing resources by killing environments. 
Table 1. Future Threads

\begin{tabular}{|l|l|}
\hline Ecological problems & Resources \&t areas damaged \\
\hline A huge surge of water level & Control of coasts \\
\hline $\begin{array}{l}\text { Increased rain outbreaks, crop failures, } \\
\text { earthquakes, warmer temperatures }\end{array}$ & Pitfalls on Human Wellbeing \\
\hline A scenario of Glacial Melt & Workforce and resources \\
\hline Transition of consistency and volume of water & Distribution of Water \\
\hline $\begin{array}{l}\text { Disparities in variations of rainfall } \\
\text { Variability of conditions and } \\
\text { regions of development }\end{array}$ & $\begin{array}{l}\text { Plans for Disaster } \\
\text { Management \& Restoration }\end{array}$ \\
\hline
\end{tabular}

We believe a much more vital aspect of our life than statistics in general with our viewpoint on nature, readers should embrace the part of nature in each of the respective work on green literature. The description in green literature is so wonderful and natural for its genre that it must have an undeniable place in every record of its specialization. Erotic gratification is what it seeks in nature; it is also receptive to the richness of the earth, and the bond between man and soil. Rethinking the art of Green Writing, one would hopefully understand that it would be the supreme and ulterior problem to embrace and integrate a happy and better relationship between humans and nature. The inclusion of ecocritical values into the work of literature itself is preferably about reexamining accompanied by re-evaluating the sense of perspective that the framework of the contemporary age should value.

\section{CONCLUSION}

The Romanticists had seen the potential of nature, which they consciously responded to as the beauty of the world declined in times of industrialization. Today, in its artistic reaction, literature must stand for nature to respond to the breaking down of Mother Earth. Literature is not only a script that is written, but what is conveyed in different media. Visual contact now plays an important part in people's lives. We all learn that even by making falsity as reality, how a movie or news will persuade viewers. Through different messages, the persistent projection of consciousness of ecological problems and eco-friendliness could be ingrained throughout the minds of individuals. Our lifestyle, looking up to nature, still needs to be improved. As Vandana Shiva says, she learned it all from the forests. We ought to switch to the physical world, further from the virtual environment. Nature will show us much more than what is learned in the education curriculum. A human who is attuned to nature was a very well entity that is receptive to creatures. The consumeristic society of today distracts us and makes us feel unsatisfied with products that we have for the intent of gain. So, let us benefit from the natural world to evolve in peace as one amongst the other inhabitants.

\section{REFERENCES}

Altieri, M.A. (1995). Agro Ecology: The Science of Sustainable Agriculture. 2nd edition. Westview Press, Boulder.

Arndt, H.W. (1987). Economic Development: The History of an idea. University of Chicago Press, Chicago.

Branch, Michael Pl and Scott Slovic (2003). The ISLE Reader: Ecocriticism, 1993-2003. Athens: University of Georgia Press.

Buell, Lawrence (2005). The Future of Environmental Criticism: Environmental Crisis and Literary Imagination. Oxford: Blackwell, Print.

Demaline, Kristen. (2014). Years of Living Dangerously Recap; Episode 8, A Dangerous Future. Ecocentric, Grace Communications Foundation, June 3.

Giblett, Rodney James (1996). Postmodern Wetlands: Culture, History, Ecology. Edinburgh University Press. Glotfelty, Cheryll and Harold Fromm, eds (1996). The Ecocriticism Reader: Landmarks in Literary Ecology. Georgia: Georgia UP, Print.

Haraway, Donna J (1998). "Situated Knowledges". Feminist Studies, pp. 575-99. Print.

Jimmy, Neema Bagula. (2015) Ecocritical Approach to Literary Text Interpretation. International Journal of Innovation and Scientific Research ISSN 2351-8014 Vol. 18 No. 2 Oct., pp. 369-378.

Kincaid, Jamaica (1999). "Allen Soil". Literature and the Environment: A Reader on Nature and Culture. Eds. Loraine Anderson, Scott Slovic and John O'Grady. New York: Longman, pp. 327-332.

Mahmood, Shakeel Ahmed. (2012). Impact of Climate Change in Bangladesh: The Role of Public Administration and Government's Integrity. Journal of Ecology and the Natural Environment Vol. 4(8), pp. 223-240, May. Ravindranath, N.H., Rao, Sandhya. et.al. (2011). Climate change vulnerability profiles for North East India. Special Edition, Current Science, Vol. 101, No. 3. August 10. 
Rueckert, William (1996). "Literature and Ecology: An Experiment in Ecocriticism”. The Ecocriticism Reader: Landmarks in Literary Ecology. Eds. Glotfelty and Fromm Georgia: Georgia UP, pp. 105-123. Print.

Sherjit Singh L and Dhar, I. (2017). Floods in Imphal Valley-Causes, Effects and Preventive Measures. International Journal of Engineering Technology, Management and Applied Sciences. v.5 (9): pp. 7-11. Shiva, Vandana. (1988). Staying Alive: Women, Ecology and Development. London: Zed Books. Print.

Singh, L. Sherjit and Singh, KhMohon. (2017). Global
Warming and Its Impacts in Manipur, Northeast India. International Journal of Engineering Technology Science and Research IJETSR. ISSN 2394 - 3386 Volume 4, Issue 11.

Somanathan E. and Somanathan, Rohini. (2009). Climate Change: Challenges Facing India's Poor. Economic \& Political Weekly EPW, vol. xliv no. 31.

Thomas, Thejas G. and Kumar, Prasantha N.S. (2019). A Portrayal of Ecological Perspectives on Climate Change in Indian Cinema. International Journal of Recent Technology and Engineering. ISSN: 2277-3878, Volume-8 Issue-3, September. 